\title{
DEPRESSÃO NA TERCEIRA IDADE: A CONTRIBUIÇÃO DO ENFERMEIRO PARA A RECUPERAÇÃO DOS IDOSOS DEPRESSIVOS NA ATENÇÃO BÁSICA
}

\section{ARTIGO DE REVISÃO}

SILVA, Jardeane Santos ${ }^{1}$, QUEIROZ, Patrícia dos Santos Silva², MEDEIROS, Felype Hanns Alves de ${ }^{3}$, JUNIOR, Francisco Alves Lima ${ }^{4}$, TOURINHO, Erika Ferreira $^{5}$

SILVA, Jardeane Santos. Et al. Depressão na terceira idade: a contribuição do enfermeiro para a recuperação dos idosos depressivos na atenção básica. Revista Científica Multidisciplinar Núcleo do Conhecimento. Ano 06, Ed. 09, Vol. 03, pp. 27-44. Setembro de 2021. ISSN: 2448-0959, Link de acesso: https://www.nucleodoconhecimento.com.br/psicologia/idosos-depressivos, DOI: 10.32749/nucleodoconhecimento.com.br/psicologia/idosos-depressivos

\section{RESUMO}

Os idosos depressivos necessitam de cuidados que vão além das expressões físicas e biológicas. Diante do exposto, o presente artigo tem como questão norteadora: Como o enfermeiro pode ajudar na recuperação dos idosos depressivos? O objetivo do presente estudo consiste em analisar na literatura a contribuição do enfermeiro para a recuperação dos idosos depressivos na Atenção Básica. O presente trabalho consiste em uma pesquisa bibliográfica desenvolvida através do método da Pesquisa Narrativa. Para coletar os dados foi realizada uma investigação nas bases de dados: Biblioteca Virtual em Saúde (BVS), Literatura Latino-Americana em Ciências de Saúde (LILACS), Base de Dados Bibliográficos Especializada na Área

\footnotetext{
${ }^{1}$ Graduanda em Enfermagem pela Universidade CEUMA.

${ }^{2}$ Mestre.

${ }^{3}$ Especialista em Terapia Intensiva pela FABIC e Mestrando em Cirurgia Experimental pela UEPA.

${ }^{4}$ Mestre.

${ }^{5}$ Mestre.
}

RC: 96902

Disponível em: https://www.nucleodoconhecimento.com.br/psicologia/idososdepressivos 
de Enfermagem e Scientific Electronic Library Online (SCIELO). Os critérios de inclusão foram: artigos publicados no período de 2015 a 2021 na língua portuguesa. Foram excluídos durante a busca: produções duplicadas e textos que não estavam disponíveis na íntegra. Quanto aos resultados, evidenciou-se que conhecer os fatores de riscos associados a depressão e a realização de estratégias preventivas no âmbito da atenção primária favorece aos enfermeiros estratégias para assegurar o envelhecimento ativo e a promoção da saúde mental da população idosa, auxiliando no processo de recuperação. Conclui-se que as estratégias utilizadas pelo enfermeiro são de suma importância na recuperação do paciente, pois a sua função diante da depressão dos idosos se baseia na orientação acerca da importância do uso de medicamentos, esclarecimentos de dúvidas deste público e atender suas demandas com carinho e atenção.

Palavras-chave: Idoso, Estratégias, Enfermeiro, Depressão.

\section{INTRODUÇÃO}

Através dos estudos bibliográficos realizados constatou-se que a depressão na terceira idade vem crescendo de forma exacerbada, fazendo com que a rede de saúde tenha um olhar mais atencioso com esta população. O profissional da saúde, especialmente o enfermeiro, desempenha um papel significativo na vida do idosos, uma vez que ele pode ajudar e auxiliar a sair desse estado de depressão. Para que tal fato ocorra de forma satisfatória, faz-se necessário a participação da família para que este combate depressivo seja extinguido (DANTAS, 2018).

O papel desempenhado pelo enfermeiro diante desse cenário é de vital importância para contribuir na recuperação do paciente que se encontra com depressão, ao mesmo tempo que, a prevenção contempla o envolvimento dos profissionais da saúde e da família do idoso depressivo, podendo ser incluído características biopsicossociais e espirituais (QUEIROZ, 2020). 
Independentemente da situação econômica, social, religiosa, afetiva ou racial, qualquer ser humano está sujeito a depressão. A depressão deve ser compreendida como uma síndrome psiquiátrica da modernidade. Os dados são que aproximadamente $17 \%$ da população mundial é acometida de depressão, sendo duas vezes maior quando se trata da população feminina. Nos EUA, por exemplo, a mesma atinge aproximadamente $9,5 \%$ dos adultos por ano (PEREIRA et al, 2019).

O enfermeiro pode auxiliar os pacientes em questão a ter uma qualidade de vida satisfatória, além de orientar os idosos a terem uma vida mais independente, com autonomia e auxiliando os idosos depressivos a terem mais autoestima, permitindo que eles resgatem a sua cidadania (QUEIROZ, 2020).

O profissional da saúde comprometido com o seu papel deve auxiliar o idoso a diminuir o sofrimento psíquico pela depressão, evitando que eles recorram ao suicídio, possibilitando aos idosos a terem uma qualidade de vida melhor (SILVA et al, 2019).

A depressão é uma síndrome psiquiátrica que está relacionada com os sintomas de caráter: psicológico, comportamental e físico. A depressão entre os idosos vem crescente de forma significativa, onde uma boa parte, procuram ajuda para retornarem as suas vidas (SILVA et al, 2019). Diante do exposto, pergunta-se: Como o enfermeiro pode ajudar na recuperação dos idosos depressivos?

O interesse em realizar essa pesquisa surgiu pelo fato de conhecer a saúde, mais especificamente a Atenção Básica, e consequentemente perceber que os casos de depressão na terceira idade vem crescendo de forma assustadora nos últimos anos. Para não ter que enfrentar as consequências é de fundamental importância que a anamnese do paciente realizada pelo enfermeiro seja detalhada, contando com o apoio da família ou cuidadores.

O objetivo do presente estudo consiste em analisar na literatura a contribuição do enfermeiro para a recuperação dos idosos depressivos na Atenção Básica. E os específicos são: identificar como se apresenta a depressão na terceira idade;

RC: 96902

Disponível em: https://www.nucleodoconhecimento.com.br/psicologia/idososdepressivos 
compreender a relação familiar do idoso em relação a recuperação do quadro depressivo e identificar o papel do profissional de enfermagem para o atendimento e recuperação do idoso depressivo.

\section{METODOLOGIA}

A metodologia ajuda o pesquisador a responder os questionamentos a respeito da temática levantada, nesse caso, o "Depressão na Terceira Idade", em observância a contribuição do enfermeiro para a recuperação dos idosos depressivos na atenção básica.

O método é o caminho a ser percorrido para que o objetivo da pesquisa seja alcançado. Para Lakatos e Marconi (2017, p. 12) o método "é o caminho a ser trilhado pelos pesquisadores na busca do conhecimento": é o traçado das etapas fundamentais da pesquisa.

Este trabalho consiste em uma pesquisa bibliográfica desenvolvida através do método da Pesquisa Narrativa. A pesquisa bibliográfica é fundamental nas práticas de investigações, pois através dos registros publicados, o investigador tem a oportunidade de encontrar respostas de lacunas existentes (MARCONI; LAKATOS, 2017).

Por outro lado, segundo Aimi (2020, p. 3), "uma narrativa é composta por uma sequência singular de eventos, estados mentais, ocorrências envolvendo seres humanos como personagens ou autores" e acrescenta, mais à frente que "ela pode ser "real" ou "imaginária" sem perder seu poder como história".

Para coletar os dados foi realizada uma investigação nas bases de dados: Biblioteca Virtual em Saúde (BVS), Literatura Latino-Americana em Ciências de Saúde (LILACS), Base de Dados Bibliográficos Especializada na Área de Enfermagem e Scientific Electronic Library Online (SCIELO). Os critérios de inclusão foram: artigos publicados no período de 2015 a 2021, na língua portuguesa, com temas voltados 
para a contribuição do enfermeiro para a recuperação dos idosos depressivos na Atenção Básica.

Os critérios de inclusão utilizados para a seleção da amostra foram: a Biblioteca Virtual em Saúde (BVS), Literatura Latino-Americana em Ciências de Saúde (LILACS), Medline, Base de Dados Bibliográficos Especializada na Área de Enfermagem e Scientific Electronic Library Online (SCIELO). Foram excluídos durante a busca: produção duplicada, editoriais, cartas ao editor, boletins epidemiológicos.

A avaliação crítica dos estudos selecionados consistiu-se na leitura na íntegra destes (prisma), seguida da elaboração de quadros contendo ano de publicação e sujeitos do estudo.

A investigação da temática foi realizada fazendo uso do cruzamento das palavraschave: Idoso. Estratégias. Enfermeiro. Depressão. Os critérios de inclusão utilizados para a seleção da amostra foram: artigos publicados no período de 2015 a 2021, idioma português, relação com a temática pesquisada. Foram excluídos durante a busca: produção duplicada e não disponível na íntegra.

Portanto, inicialmente, através da busca nas bases de dados, foram encontrados 242 artigos. Após adicionamento dos filtros, restaram 105 artigos. Realizada a leitura dos títulos dos artigos, notou-se que os trabalhos que tinham relação com o tema estudado ou não estavam repetidos, eram 78. Após a leitura dos resumos, foram selecionados 15 artigos que preenchiam os critérios propostos.

\section{RESULTADOS}

A amostra final desta revisão foi constituída por 15 (quinze) artigos científicos, selecionados pelos critérios de inclusão previamente estabelecidos. O quadro 1 representa as especificações de cada um dos artigos, distribuídos, segundo: ano de publicação; periódico; autores; título e tipo de pesquisa. 
Quadro 1. Artigos levantados para Pesquisa Narrativa.

\begin{tabular}{|c|c|c|c|c|}
\hline ANO & PERIÓDICO & AUTORES & TÍTULO & $\begin{array}{l}\text { TIPO DE } \\
\text { PESQUISA }\end{array}$ \\
\hline 2018 & $\begin{array}{ll}\text { Centro } & \text { de } \\
\text { Formação } & \text { de } \\
\text { Professores } & \end{array}$ & $\begin{array}{l}\text { DANTAS, } \\
\text { Isadora Leite } \\
\text { Alves }\end{array}$ & $\begin{array}{l}\text { Assistência ao } \\
\text { idoso que convive } \\
\text { com depressão na } \\
\text { atenção básica: } \\
\text { revisão narrativa de } \\
\text { literatura }\end{array}$ & $\begin{array}{l}\text { Revisão } \\
\text { narrativa } \\
\text { literatura }\end{array}$ \\
\hline 2020 & $\begin{array}{ll}\text { Braz. J. of } \\
\text { Develop }\end{array}$ & $\begin{array}{l}\text { FIDELIS, Jailson } \\
\text { Alves }\end{array}$ & 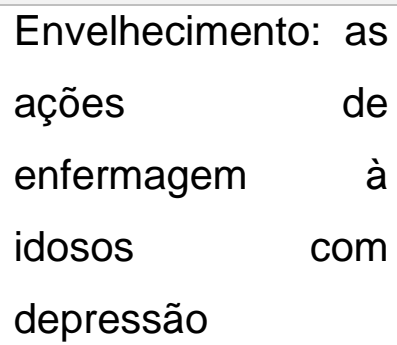 & $\begin{array}{l}\text { Revisão } \\
\text { bibliográfica, } \\
\text { qualitativa }\end{array}$ \\
\hline 2019 & $\begin{array}{l}\text { Núcleo } \\
\text { Interdisciplinar de } \\
\text { Pesquisa }\end{array}$ & $\begin{array}{l}\text { GUIMARÃES, } \\
\text { Ana Paula } \\
\text { Rodrigues }\end{array}$ & $\begin{array}{l}\text { A contribuição do } \\
\text { enfermeiro na } \\
\text { recuperação de } \\
\text { idosos depressivos }\end{array}$ & $\begin{array}{l}\text { Revisão } \\
\text { literatura }\end{array}$ \\
\hline 2017 & $\begin{array}{l}\text { Revista Científica } \\
\text { da FASETE }\end{array}$ & $\begin{array}{l}\text { LIMA, Vilne Jean } \\
\text { Santos de }\end{array}$ & $\begin{array}{l}\text { Cuidados de } \\
\text { enfermagem à } \\
\text { pessoa com } \\
\text { depressão atendida } \\
\text { na atenção primária } \\
\text { de saúde }\end{array}$ & $\begin{array}{l}\text { Revisão } \\
\text { integrativa }\end{array}$ \\
\hline 2020 & $\begin{array}{l}\text { Brazilian Journal } \\
\text { of Development }\end{array}$ & $\begin{array}{l}\text { LIMA, Taciana } \\
\text { Maria, et al }\end{array}$ & $\begin{array}{l}\text { Intervenções de } \\
\text { enfermagem em } \\
\text { idosos depressivos: } \\
\text { uma revisão da } \\
\text { literatura }\end{array}$ & $\begin{array}{l}\text { Revisão } \\
\text { literatura }\end{array}$ \\
\hline 2015 & Ciência \& Saúde & MINAYO, Maria & Tentativas & Revisão \\
\hline
\end{tabular}

RC: 96902

Disponível em: https://www.nucleodoconhecimento.com.br/psicologia/idosos- 


\begin{tabular}{|c|c|c|c|c|}
\hline & Coletiva & $\begin{array}{l}\text { Cecília de } \\
\text { Souza; } \\
\text { CAVALCANTE, } \\
\text { Fátima } \\
\text { Gonçalves }\end{array}$ & $\begin{array}{l}\text { suicídio entre } \\
\text { pessoas idosas: } \\
\text { revisão de literatura } \\
(2002 / 2013)\end{array}$ & literatura \\
\hline 2019 & $\begin{array}{l}\text { Centro } \\
\text { Universitário } \\
\text { Luterano de } \\
\text { Palmas }\end{array}$ & $\begin{array}{l}\text { MORAES, Karlla } \\
\text { Suellen Belem }\end{array}$ & $\begin{array}{lr}\text { Assistência } & \text { de } \\
\text { enfermagem } & \text { a } \\
\text { pacientes } & \\
\text { portadores } & \text { de } \\
\text { depressão } & \text { na } \\
\text { terceira idade } & \end{array}$ & $\begin{array}{l}\text { Revisão } \\
\text { bibliográfica }\end{array}$ \\
\hline 2019 & $\begin{array}{l}\text { Revista } \\
\text { Enfermagem } \\
\text { Digital Cuidado e } \\
\text { Promoção da } \\
\text { Saúde }\end{array}$ & $\begin{array}{l}\text { PEREIRA, } \\
\text { Brenda Roberta } \\
\text { da Silva, et al }\end{array}$ & $\begin{array}{l}\text { Atuação da } \\
\text { enfermagem frente } \\
\text { à depressão na } \\
\text { população idosa }\end{array}$ & $\begin{array}{l}\text { Revisão } \\
\text { Integrativa }\end{array}$ \\
\hline 2020 & $\begin{array}{l}\text { Faculdade } \\
\text { Esperança de } \\
\text { Mossoró }\end{array}$ & $\begin{array}{l}\text { QUEIROZ, } \\
\text { Antonia Fabiana }\end{array}$ & $\begin{array}{l}\text { Assistência de } \\
\text { enfermagem na } \\
\text { atenção básica a } \\
\text { pessoa idosa com } \\
\text { transtorno } \\
\text { depressivo: uma } \\
\text { revisão integrativa }\end{array}$ & $\begin{array}{l}\text { Revisão } \\
\text { Integrativa }\end{array}$ \\
\hline 2019 & $\begin{array}{l}\text { Il Congresso } \\
\text { Nacional de } \\
\text { Envelhecimento } \\
\text { Humano }\end{array}$ & $\begin{array}{l}\text { SILVA, Ledilson } \\
\text { Ribeiro da, et al }\end{array}$ & $\begin{array}{l}\text { Assistência de } \\
\text { enfermagem a } \\
\text { pessoa idosa com } \\
\text { depressão }\end{array}$ & $\begin{array}{l}\text { Revisão } \\
\text { Integrativa }\end{array}$ \\
\hline 2017 & $\begin{array}{l}\text { Faculdade Pan- } \\
\text { Amazônica }\end{array}$ & $\begin{array}{l}\text { SILVA, Geise } \\
\text { Rolim da; } \\
\text { NASCIMENTO, }\end{array}$ & $\begin{array}{lr}\text { A assistência } & \text { da } \\
\text { enfermagem } & \text { no } \\
\text { idoso } & \text { com }\end{array}$ & $\begin{array}{l}\text { Revisão } \\
\text { literatura }\end{array}$ \\
\hline
\end{tabular}

RC: 96902

Disponível em: https://www.nucleodoconhecimento.com.br/psicologia/idosos- 


\begin{tabular}{|c|c|c|c|c|}
\hline & & Indianara do & $\begin{array}{l}\text { depressão: Revisão } \\
\text { Integrativa da } \\
\text { Literatura }\end{array}$ & \\
\hline 2021 & $\begin{array}{l}\text { Research, } \\
\text { Society and } \\
\text { Development }\end{array}$ & $\begin{array}{ll}\text { SILVA, } & \text { Brenda } \\
\text { Caroline } & \text { Martins } \\
\text { da, et al } & \end{array}$ & $\begin{array}{lr}\text { Importância } & \text { da } \\
\text { identificação } & \text { do } \\
\text { diagnóstico } & \text { de } \\
\text { enfermagem } & \text { ao } \\
\text { paciente } & \text { com } \\
\text { depressão senil na }\end{array}$ & $\begin{array}{l}\text { Relato de } \\
\text { experiência, } \\
\text { de natureza } \\
\text { descritiva, } \\
\text { com } \\
\text { abordagem } \\
\text { qualitativa }\end{array}$ \\
\hline 2018 & $\begin{array}{l}\text { Revista Científica } \\
\text { do } \\
\text { UNISALESIANO }\end{array}$ & $\begin{array}{l}\text { TOFANELLI, } \\
\text { Amanda Heloisa } \\
\text { da Cruz Figueira }\end{array}$ & $\begin{array}{l}\text { Sintomas } \\
\text { depressivos em } \\
\text { mulheres idosas: } \\
\text { Aplicando a Escala } \\
\text { de Depressão } \\
\text { Geriátrica de } \\
\text { Yesavage }\end{array}$ & $\begin{array}{l}\text { Pesquisa } \\
\text { exploratória e } \\
\text { descritiva com } \\
\text { abordagem } \\
\text { quantitativa }\end{array}$ \\
\hline 2016 & $\begin{array}{l}\text { Revista Eletrônica } \\
\text { Gestão \& Saúde }\end{array}$ & $\begin{array}{l}\text { TREVISAN, } \\
\text { Mauro, et al }\end{array}$ & $\begin{array}{l}\text { O papel do } \\
\text { enfermeiro na } \\
\text { recuperação de } \\
\text { idosos depressivos }\end{array}$ & $\begin{array}{l}\text { Revisão da } \\
\text { literatura }\end{array}$ \\
\hline 2019 & $\begin{array}{l}\text { Rede nordeste de } \\
\text { formação em } \\
\text { saúde da família }\end{array}$ & $\begin{array}{l}\text { VERAS, Carla } \\
\text { Nayara dos } \\
\text { Santos Souza }\end{array}$ & $\begin{array}{lr}\text { Conhecimento de } \\
\text { enfermeiros sobre } \\
\text { sintomas } \\
\text { depressivos } \\
\text { idosos em } \\
\text { instrumentos } \\
\text { rastreio }\end{array}$ & $\begin{array}{l}\text { Estudo } \\
\text { descritivo com } \\
\text { abordagem } \\
\text { qualitativa }\end{array}$ \\
\hline
\end{tabular}

Fonte: autoria própria (2021)

RC: 96902

Disponível em: https://www.nucleodoconhecimento.com.br/psicologia/idososdepressivos 


\section{DISCUSSÃO}

A designação do termo depressão era totalmente diferente dos dias atuais. Antigamente a depressão era chamada de melancolia, designava sintomas ou estados mentais, termo designado há 25 séculos atrás. Além de ser vista como uma doença mental, a mesma apresentava outros sintomas. Estado emocional muito baixo, é um exemplo, onde a pessoa se sentia infeliz, desanimado e triste (DANTAS, 2018).

A partir do século XVII, a definição de melancolia, juntando com os conhecimentos teóricos da psiquiatria, este tipo de termo e a concepção que tinha em relação sobre a depressão foi modificado. Somente no século XIX, o termo melancolia, foi vista e percebida como insanidade parcial, esta contribuição sobre esta nova visão veio de Pinel (FIDELIS, 2020).

Segundo Guimarães (2019), o tratado de Kraepelin em sua 6르 edição, a designação depressão passou a ter o título de doença, onde foi chamada de "psicose maníacadepressiva". Durante todo o século XX foram realizados vários estudos para entender de fato os fatores e como esta doença se apresentava. Os estudos tinham por finalidade de entender se a depressão era provocada por fatores externos ou se era uma doença que a pessoa já nascia com ela. Além de realizarem um estudo voltado para compreender os termos unipolar e bipolar.

De acordo com os estudos realizados por Dantas (2018), deixam claro que a depressão é uma emoção mundialmente sofrida de forma virtual por todas as pessoas em um período específico de suas vidas. A depressão encontra-se relacionada à estrutura melancólica, onde a mesma está baseada nas regressões e fixações da segunda subfase oral (FIDELIS, 2020).

Deve-se compreender que, a depressão é uma alteração afetiva, sendo uma das doenças mais estudadas e presentes no século XXI. É classificada como um transtorno de humor, onde faz com o que a pessoa modifique os seus 
comportamentos, além de permitir uma modificação brusca sobre a visão que tem de si mesmo, ou seja, a pessoa depressiva não consegue resolver os seus problemas o mais simples que seja, ela passa a perceber que os problemas enfrentados são uma tragédia (GUIMARÃES, 2019).

A depressão é popularmente conhecida por alguns sintomas específicos como apatia, irritabilidade, tristeza, redução da velocidade motora ou agitação, ideias agressivas, reclusão, insônia, fadiga, entre outros. O diagnóstico para sua identificação pode ser mais bem compreendido quando se tem um bom conhecimento teórico sobre o assunto (DANTAS, 2018).

Para Lima et al (2020), no contexto clínico, o termo depressão não diz respeito apenas a pessoa com humor deprimido, mas também quando se apresenta um complexo sindrômico caracterizado por alterações de humor, de psicomotricidade e por uma gama de distúrbios somáticos e neurovegetativos.

Por mais que se tenha realizados vários estudos acerca da temática em questão, ainda não chegaram em um ponto comum para saberem quais os fatores que contribuem para o estado depressivo da pessoa, se estas mudanças de humor são provocadas por fatores biológicos, sociais e ou psicológicos. Vários estudos estão sendo realizados para chegar uma conclusão sobre a depressão, mas antes de chegar nos resultados finais, se faz necessário que a pessoa depressiva procure ajuda, como: psicólogo, psiquiatra, enfermeiros entre outros para auxiliar em seu tratamento (LIMA, 2017).

A população idosa vem crescendo de forma significativa ao longo dos anos e isto faz com que o Estado e a própria sociedade civil busquem mecanismos para ter uma atenção mais direcionada para este público, haja vista que, a população idosa requer uma atenção cuidadosa, pois os mesmos apresentam mais doenças degenerativas, além da depressão. Essa doença tem atingido grandes proporções no grupo da terceira idade, fazendo necessário mais atenção para que possa haver a prevenção e controle dos casos. (LIMA, 2021). 
Deve-se entender que, por mais que o idoso tenha uma probabilidade maior em desenvolver doenças, é importante deixar claro que envelhecer não seja entendido como adoecer, especialmente as que desenvolvem hábitos de vida saudáveis (MINAYO; CAVALCANTE, 2015).

Segundo Fidelis (2020), a depressão é uma síndrome, está na terceira idade envolve inúmeros aspectos, tais como: clínicos, etiopatogênicos e de tratamento. Quando o tratamento ocorre de forma tardia, acaba se associando com as doenças clínicas, com as anormalidades estruturais e funcionais do cérebro. É por este motivo que se faz necessário que o tratamento da depressão seja realizado o mais rápido possível, evitando a morbilidade.

A depressão diz respeito a uma enfermidade mental que ocorre com grande frequência com idosos, contribuindo para um aumento significativo de sofrimento psíquico. Na população geral, a depressão tem prevalência em torno de $15 \%$; em idosos que vivem na comunidade, essa prevalência pode ainda ser de 2 e 14\% e em idosos que se encontram alojados em instituições, a prevalência da depressão chega a 30\% (MORAES, 2019).

São vários fatores que impulsionam a depressão nos idosos, pode-se citar como: luto, abandono, doenças, incapacidades entre outros. A depressão no idoso faz com que ele perca a sua qualidade de vida, haja vista que, o mesmo se isola da sociedade, fator este que é primordial para o aparecimento de doenças clínicas que são consideradas graves (MINAYO; CAVALCANTE, 2015).

Para saber se o paciente apresenta depressão, se faz necessário que realize algumas etapas no diagnóstico. A primeira dela é a anamnese do idoso, quando não reconhece a pessoa cuida dele ou seus familiares. $O$ exame psiquiátrico deve ser realizado de forma detalhada e minuciosa para saber se o idoso tem alguma característica da depressão. A avaliação neurológica é de grande valia neste diagnóstico. A identificação das medicações que apresentam as suas adversidades, os exames de laboratório e de os exames de neuroimagem (MORAES, 2019). 
A depressão na terceira idade está mais associada com as questões físicas, isto significa que, quando os idosos apresentam dependência física, automaticamente perde a sua autonomia, onde uma boa parcela destes idosos acabam ficando hospitalizados ou em instituições de asilo. Em muitos casos os sintomas de depressão nos idosos são confundidos com a sua própria patologia, fazendo com que acabe ignorando a depressão, ficando cada vez mais debilitado, as vezes chegando até a morte (MINAYO; CAVALCANTE, 2015).

O idoso quando está com depressão, ele se recusa que alguém cuide dele, não se alimenta, além de não seguir as recomendações do médico. Quando ele não ajuda neste tratamento depressivo, implica diretamente para a diminuição da sua imunidade e desta forma permitindo a ele que tenha mais processos infeciosos (PEREIRA et al, 2019).

O objetivo primordial para o tratamento da depressão na terceira idade é de amenizar o sofrimento psíquico, fazendo que os casos de suicídios diminuam, além de permitir aos pacientes sintam-se bem, para que possa ter uma qualidade de vida. É neste tocante que o enfermeiro tem um papel de grande valia para o tratamento da depressão na terceira idade (QUEIROZ, 2020).

É importante que os profissionais da saúde, especialmente o enfermeiro, possam saber a forma adequada para identificar a depressão. Este trabalho de identificação da depressão se torna mais eficiente quando a mesma tem a participação de uma equipe multidisciplinar, os resultados são mais eficientes. Este trabalho deve ser realizado em parceria para que o idoso tenha a sua qualidade de vida (PEREIRA et al, 2019).

O Enfermeiro precisa ser conhecedor da depressão e de seus sintomas, pois ele precisa saber como identificar não somente tentativas óbvias de suicídio, mas, também, as sutis e igualmente destrutivas, entre elas está a ingestão inadequada e proibida de fármacos, a prática de ações que vão contra ao que de fato precisa. $O$ idoso que apresente alguma propensão ao risco de suicídio precisa de uma 
observação mais próxima, sendo urgente a terapia imediata. O idoso precisa estar inserido em um ambiente seguro com profissional que esteja de fato disposto a ouvir (MORAES, 2019).

No decurso da história brasileira, as instituições vêm sofrendo mudanças decorrentes da dinamicidade econômica, política e social. Uma dessas instituições que mais tem chamado atenção é o modelo de família. No entanto a mesma continua sendo a célula principal dentro da constituição da sociedade. A família é um primeiro núcleo social que a criança tem contato (QUEIROZ, 2020).

A família tem um papel significativo para a melhoria da depressão do idoso, é fundamental que a família trabalhe em parceria com o enfermeiro, haja vista que, um trabalho conjunto favorece um trabalho produtivo, eficaz e eficiente, permitindo assim ao idoso depressivo a uma qualidade de vida mais rápida e satisfatória (MINAYO; CAVALCANTE, 2015).

O enfermeiro deve estar atento às necessidades particulares do idoso depressivo, observando, verificando, analisando e percebendo quais as dificuldades, os seus anseios, pois é a partir desta análise que o mesmo deve comunicar a família sobre as observações tidas e juntamente com a equipe multidisciplinar buscar mecanismos para sanar a depressão (SILVA et al, 2019).

O papel do enfermeiro não está voltado apenas em fazer um acompanhamento do idoso depressivo, perpassa muito mais do que isto. $O$ enfermeiro não apenas esclarece as dúvidas que vierem a surgir, explicando de que forma será as terapias, as questões das medicamentações. Compete a ele também a ouvir, a compreender o idoso depressivo. Deve ser um apoio, um suporte para o idoso. Cabe a ele também orientar a família de forma adequada a situação de como está o paciente e quais os mecanismos, os suportes que devem utilizar para o tratamento da depressão (PEREIRA et al, 2019).

O enfermeiro necessita ser afetivo para com o idoso depressivo. A afetividade é um dos elementos de suma importância para o tratamento da depressão, especialmente

RC: 96902

Disponível em: https://www.nucleodoconhecimento.com.br/psicologia/idososdepressivos 
para com os idosos. É ela que provoca interesse, a motivação para a sua recuperação. A recuperação da depressão é constituída a partir das relações do indivíduo com o meio, assim como o sujeito com o outro. E nessa interação a afetividade age como um elo que vem abrindo fronteiras para que as mais variadas formas de emoções possam em conjunto ampliar e ou reforçarem o tratamento da depressão na velhice (SILVA et al, 2019).

O desenvolvimento da dimensão afetiva é o alicerce para desenvolvimento do ser humano. De acordo com o dicionário de Filosofia (abbagnano), a afetividade são as emoções positivas que se referem a pessoas e que não tem o caráter dominante e totalitário da paixão. Nesse sentido a afetividade pode ser considerada uma emoção vinculada às relações interpessoais (TOFANELLI, 2018).

Quando umas situações interferem na estruturação afetiva do homem, vai refletir na totalidade do indivíduo, isto é, vai modificar a sua eficácia inteligível, assim como suas atitudes e valores. Partindo desse entendimento pode-se afirmar da importância que se deve ter em relação à formação afetiva do ser humano (SILVA et al, 2019).

Diante do exposto, percebe-se que a afetividade é um elemento intrínseco a condição humana, que influi e é influenciado por todas as ações do ser humano. Ela quando se manifesta de forma positiva, isto é, quando ela se faz sentir pela expressão de alegria, de perseverança, de agrado, torna-se um elemento de potencial relevante nas relações humanas, o que faz aumentar a produtividade do homem em relação ao meio, no qual está inserido (TOFANELLI, 2018).

A afetividade é o componente da ação. Nessa perspectiva entende-se que a afetividade é uma condição psíquica que a partir de um contexto concreto ou subjetivo pode ser ou não alterado. A mesma é de suma importância em todo o processo de desenvolvimento do ser humano (PEREIRA et al, 2019).

Compete ao enfermeiro, coordenar, planejar, supervisionar, os serviços prestados por equipes de saúde. Ele deve prestar atenção ao paciente, além de fazer este

RC: 96902

Disponível em: https://www.nucleodoconhecimento.com.br/psicologia/idososdepressivos 
acompanhamento para saber o nível de evolução do paciente. Deve ter um diálogo aberto e flexível, atendendo os pacientes com serenidade e compromisso (TREVISAN et al, 2016).

Diante desta nova realidade, as competências do enfermeiro é de promover intervenções, estas que podem contemplar todos os anseios e necessidades da população local. Curar, promover e proteger a saúde do cidadão é outra competência do enfermeiro. É importante que ele busque ações, estratégias em que possa promover a articulação do conhecimento com as experiências, para que possa auxiliar o idoso na sua cura contra a depressão (PEREIRA et al, 2019).

O trabalho do Enfermeiro com o idoso depressivo deve ser voltado para um trabalho humano, um olhar diferenciado, respeitando as particularidades dos idosos, como também conhecer de forma mais próxima a verdadeira realidade social que o ele vivência. Quando o mesmo passa a ter este tipo de postura, desperta no paciente a importância do acolhimento e da solidariedade para com o outro e ainda faz com que haja um desenvolvimento, seja nos aspectos físicos ou emocionais, fortalece no que diz respeito ao reconhecimento dos limites do idoso depressivo (TREVISAN et al, 2016).

O enfermeiro tem um compromisso com a sociedade firmando seu papel, e prestar uma melhor assistência a população. Nos faz refletir que as mudanças devem estar situadas com novas perspectivas para a enfermagem, com modificações nas políticas de saúde e no gerenciamento (MINAYO; CAVALCANTE, 2015).

O enfermeiro deve ser atencioso, cuidadoso, ético, responsável, determinado, ser afetivo com o idoso depressivo. O seu olhar não deve ser classificatório, ou apenas olhar o aspecto físico, o mesmo deve ter um lado humano, sensível, precisa entender e compreender o idoso, deve promover um diálogo aberto, onde possa acatar sugestões, estas que servirão para seu crescimento profissional e pessoal (SILVA et al, 2019). 
A atuação da família é de extrema importância para o tratamento da depressão. A família em parceria com o enfermeiro é o sustentáculo primordial em que o idoso depressivo precisa confiar para enfrentar a sua doença, e desta forma permitindo ao idoso a sua inserção no meio social (SILVA; NASCIMENTO, 2017).

O debate acerca de como fazer com que a família participe ativamente no tratamento da depressão do idoso é uma questão que tem chamado atenção de teóricos que abordam sobre a questão, como também os médicos, enfermeiros e todas que fazem parte da equipe multidisciplinar (TREVISAN et al, 2016).

Essa concepção da importância da parceria família e enfermeiro precisam ser discutidas e estimuladas. Este combate é oportuno para a contribuição no processo do tratamento depressivo do idoso, pois a interação da família é um canal aberto de ricas possibilidades de crescimento para o idoso em tratamento (MINAYO; CAVALCANTE, 2015).

A família aparece como principal suporte para o idoso depressivo, ela proporciona inúmeros benefícios para manter a saúde física e mental do idoso, ou seja, a mesma é configurada como a maior fonte de apoio na adesão ao tratamento medicamentoso e psicoterápico, e consequentemente na parte dos cuidados do lar. (PEREIRA et al, 2019).

Deve-se entender que, a família é um alicerce para o idoso depressivo, uma vez que, a mesma possibilita benefícios para manter a saúde física e mental do idoso, ela é uma fonte de apoio que auxilia o idoso depressivo a ter a sua qualidade de vida, contribuindo assim para a sua inserção ao meio social. É neste sentido que, compete ao enfermeiro incentivar os familiares para realizar o acompanhamento do idoso depressivo, para que ele possa se sentir mais seguro, permitindo que sua cura seja mais rápida (SILVA et al, 2019).

O ambiente familiar é indispensável e interfere diretamente no comportamento e nas características do idoso diariamente. Por isso, é de suma importância que a família disponibilize um ambiente saudável, que não seja propício a conflitos e que permita

RC: 96902

Disponível em: https://www.nucleodoconhecimento.com.br/psicologia/idososdepressivos 
que o idoso participe das decisões do grupo familiar onde ele está inserido (SILVA et al, 2021).

O Enfermeiro deve ser capacitado ou especializado para desempenhar as suas funções de forma eficiente e eficaz, pois ao longo da história ele vem assumindo cada vez mais responsabilidade. Esta qualificação se faz necessária para que o profissional da Enfermagem esteja preparado para questionar e acompanhar as mudanças diárias, como também refletir sobre as suas ações, a sua própria prática profissional (TOFANELLI, 2018).

Uma gama de conjuntos de mudanças tem levantado alguns pré-requisitos relevantes para a reflexão do papel do Enfermeiro. Atualmente o objetivo principal é o paciente, pois este tem direito que é lhe cabível como, por exemplo, a saúde, isso decorre do fato de que a sociedade vive uma metamorfose e casualmente o Enfermeiro também precisa acompanhar essas transformações. Por este motivo o profissional tem um papel relevante na Unidade de Atenção Básica, uma vez que, esta luta para que os pacientes/família tenham um atendimento de qualidade e com inovação aos procedimentos que lhe são oferecidos (PEREIRA et al, 2019).

"A Atenção Básica é um campo de muitas possibilidades para a saúde mental, visto que, nesse espaço, pode-se construir um cuidado integral e individualizado ao paciente com alterações psíquicas" (VERAS, 2019, p. 57).

É imprescindível que o Enfermeiro e toda equipe hospitalar formulem, arquitetem suas ações, se adequem as novas tecnologias, metodologias, sistematizem seu planejamento, suas ações voltadas para o bem-estar dos idosos depressivos (TREVISAN et al, 2016).

A qualificação do profissional do Enfermeiro deve ser contínua, pois as suas práticas sofrem mudanças de acordo com os avanços da sociedade. As suas ações devem ser significativas, assim contribuindo para o desenvolvimento pessoal, emocional, social e cultural do idoso depressivo. O mesmo tem um grande desafio a enfrentar, 
ou seja, a desenvolver ações, políticas públicas em seu ambiente de trabalho juntamente com os outros profissionais (TOFANELLI, 2018).

Os idosos depressivos necessitam de cuidados que vão além das expressões físicas e biológicas, por diversos motivos que envolvem a área de conhecimento e que se integram várias profissões que luta pela continuidade do conhecimento dos hospitalizados. É neste sentido que, se faz necessário que o profissional da Enfermagem se qualifique para saber a forma adequada de orientar e conduzir o paciente depressivo (TREVISAN, et al, 2016).

O Enfermeiro tem que apresentar-se como profissional capacitado e bem-preparado para atender os idosos e oferecer mais amor e carinho, encorajando-os para o crescimento pessoal e ao desempenho de novos papéis que estão disponíveis na sociedade, pois essas atitudes podem resgatar sua cidadania e autovalorização (TOFANELLI, 2018).

Com os avanços que a Enfermagem conseguiu durantes anos, se faz necessário que o mesmo tenha conhecimentos necessários sobre as legislações que rege, norteiam a sua área. Entender, compreender e conhecer algumas normas, estatutos, resoluções e dentre outros, se faz necessário na práxis do Enfermeiro (VERAS, 2019).

O trabalho do Enfermeiro deve ser voltado para um trabalho humano, um olhar diferenciado, respeitando as particularidades dos idosos depressivos, como também conhecer de forma mais próxima a verdadeira realidade social que o mesmo vivencia. Quando o Enfermeiro passa a ter este tipo de postura, desperta no idoso depressivo a importância do acolhimento e da solidariedade para com o outro e ainda faz com que haja um desenvolvimento, seja nos aspectos físicos ou emocionais, fortalece no que diz respeito ao reconhecimento dos limites do idoso (TOFANELLI, 2018).

A Enfermagem nunca foi uma tarefa fácil, pois ao longo desses anos foi-se necessária inovação, avanço, abrir novos caminhos, enfrentando grandes

RC: 96902

Disponível em: https://www.nucleodoconhecimento.com.br/psicologia/idososdepressivos 
dificuldades, as resistências para chegar aonde chegaram. Essas mudanças requerem muitas ações e comprometimentos, novas responsabilidades, um novo fazer e agir (TREVISAN et al, 2016).

A enfermagem vem crescendo de forma significativa, e vem conquistando cada vez mais espaço na área da saúde. Neste sentido que, o enfermeiro tem um papel relevante dentro das Unidades Básicas de Saúde, pois o mesmo cuida da população, como também a proteção na saúde os cidadãos civis em suas diferentes dimensões. Ele deve ser cada vez mais decisivo e proativo, para atender as demandas e as exigências advindas de uma nova sociedade (VERAS, 2019).

\section{CONSIDERAÇÕES FINAIS}

A partir da presente revisão narrativa pôde-se perceber que o envelhecimento é um processo fisiológico pelo qual passa todo ser humano. Desde que somos concebidos já estamos envelhecendo, esse processo se estende por toda a vida do indivíduo, sendo mais percebível por volta dos 60 anos. O envelhecimento humano é um processo natural de vulnerabilização.

Ao término da pesquisa constatou-se que a depressão é caracterizada como uma síndrome psiquiátrica envolvida por vários fatores, tais como fatores psicológicos comportamentais e físicos. Esta patologia incide em uma mudança no aspecto emocional que eleva o índice de morbidade e mortalidade entre os idosos.

O trabalho permitiu elucidar as principais causas da depressão e que a escala de depressão geriátrica é um meio simples e eficaz para detectar um quadro depressivo em idosos. O prevalecimento de depressão vem ocasionando uma preocupação significativa entre os enfermeiros por estar se referindo a uma doença que evita o idoso de ter uma melhor qualidade de vida e de se expor a riscos.

A depressão na terceira idade está mais associada com as questões físicas, isto significa que, quando os idosos apresentam dependência física, automaticamente perde a sua autonomia, onde uma boa parcela deste idosos acabam ficando

RC: 96902

Disponível em: https://www.nucleodoconhecimento.com.br/psicologia/idososdepressivos 
hospitalizados ou em instituições de asilo. Em muitos casos os sintomas de depressão nos idosos são confundidos com a sua própria patologia, fazendo com que deixa de lado a depressão, ficando cada vez mais debilitado, às vezes chegando até a morte.

A família influência no comportamento e hábitos do idoso. Por isso, é importante que a família disponibilize um lar calmo e aconchegante onde o idoso se sinta útil e importante.

O trabalho do Enfermeiro com o idoso depressivo deve ser voltado para um trabalho humano, um olhar diferenciado, respeitando as particularidades dos idosos, como também conhecer de forma mais próxima a verdadeira realidade social que ele vivência.

Dessa maneira, pode-se concluir que as estratégias utilizadas pelo enfermeiro são de suma importância na recuperação da depressão dos idosos, se baseia na orientação acerca da importância do uso de medicamentos, esclarecimentos de dúvidas deste público-alvo e atender suas demandas com mais carinho e atenção. O enfermeiro pode também estimular a autoestima e a criação de novas atividades do idoso na sociedade, incentivá-los na prática de exercícios físicos e frequentar grupos de terceira idade com o total apoio da família onde essa é de suma importância para o melhor restabelecimento da sua saúde. Assim, espera-se que esse estudo possa colaborar para uma melhor compreensão deste mal que afeta grande parte dos idosos e que é pouco diagnosticada, mas que cresce a cada dia que se passa em nossa sociedade.

\section{REFERÊNCIAS}

AIMI, Deusodete Rita da Silva. Pesquisa narrativa: reflexões sobre produções dos últimos 14 anos. Educação em Perspectiva. Viçosa, MG v. 11 p. 1-15| e 020018|2020 
DANTAS, Isadora Leite Alves. Assistência ao idoso que convive com depressão na atenção básica: revisão narrativa de literatura. Trabalho de Conclusão de Curso. Cajazeiras - PB, 2018.

FIDELIS, Jailson Alves. Envelhecimento: as ações de enfermagem à idosos com depressão. Braz. J. of Develop., Curitiba, v. 6, n. 6, p. 39597-39607, jun. 2020.

GUIMARÃES, Ana Paula Rodrigues. A contribuição do enfermeiro na recuperação de idosos depressivos. Núcleo Interdisciplinar de Pesquisa. Artigo de Revisão, 2019.

LIMA, Vilne Jean Santos de. Cuidados de enfermagem à pessoa com depressão atendida na atenção primária de saúde. Revista Científica da FASETE 2017.

LIMA, Taciana Maria, et al. Intervenções de enfermagem em idosos depressivos: uma revisão da literatura. Brazilian Journal of Development, Curitiba, v.7, n.2, p. 11870-1666666633////////1883 feb. 2020.

MARCONI, Marina; LAKATOS, Eva. Fundamentos de metodologia científica. 8. ed. São Paulo: Atlas, 2017.

MINAYO, Maria Cecília de Souza; CAVALCANTE, Fátima Gonçalves. Tentativas de suicídio entre pessoas idosas: revisão de literatura (2002/2013). Ciência \& Saúde Coletiva, 20(6):1751-1762, 2015.

MORAES, Karlla Suellen Belem. Assistência de enfermagem a pacientes portadoresde depressão na terceira idade. Monografia. Palmas-TO, 2019.

PEREIRA, Brenda Roberta da Silva, et al. Atuação da enfermagem frente à depressão na população idosa. Revista Enfermagem Digital Cuidado e Promoção da Saúde 4 (1) Janeiro/Junho 2019.

QUEIROZ, Antonia Fabiana. Assistência de enfermagem na atenção básica a pessoa idosa com transtorno depressivo: uma revisão integrativa. Trabalho de Pesquisa. Mossoró- RN, 2020.

RC: 96902

Disponível em: https://www.nucleodoconhecimento.com.br/psicologia/idososdepressivos 
SILVA, Ledilson Ribeiro da, et al. Assistência de enfermagem a pessoa idosa com depressão. Il Congresso Nacional de Envelhecimento Humano. 2019.

SILVA, Geise Rolim da; NASCIMENTO, Indianara do. A assistência da enfermagem no idoso com depressão: Revisão Integrativa da Literatura. Trabalho de Conclusão de Curso. Belém - PA, 2017.

SILVA, Brenda Caroline Martins da, et al. Importância da identificação do diagnóstico de enfermagem ao paciente com depressão senil na atenção básica. Research, Society and Development, v. 10, n.2, e53510212770, 2021.

TOFANELLI, Amanda Heloisa da Cruz Figueira. Sintomas depressivos em mulheres idosas: Aplicando a Escala de Depressão Geriátrica de Yesavage. Revista Científica do UNISALESIANO. Ano 9 - nำ 19 - Julho/Dezembro 2018.

TREVISAN, Mauro, et al. O papel do enfermeiro na recuperação de idosos depressivos. Revista Eletrônica Gestão \& Saúde. Vol.07, №. 01, Ano 2016 p.428-40.

VERAS, Carla Nayara dos Santos Souza. Conhecimento de enfermeiros sobre sintomas depressivos em idosos e instrumentos de rastreio. Trabalho de Conclusão de Mestrado. Teresina, 2019.

Enviado: Julho, 2021.

Aprovado: Setembro, 2021. 